\title{
Significant Phenylalanine Hydroxylation In Vivo in Patients with Classical Phenylketonuria
}

\author{
G. N. Thompson and D. Halliday \\ Nutrition Research Group, Clinical Research Centre, Harrow, United Kingdom
}

\begin{abstract}
Indirect measurements have previously suggested that patients with classical phenylketonuria (PKU) do not convert signifcant amounts of phenylalanine to tyrosine. Low-dose continuous infusion techniques employing $\left[{ }^{2} \mathbf{H}_{5}\right]$ phenylalanine and $\left[{ }^{2} \mathrm{H}_{2}\right]$ tyrosine were used to quantitate in vivo phenylalanine hydroxylation in 10 subjects with classical phenylketonuria, 2 with hyperphenylalaninemia (HPA), and 7 controls. Plasma phenylalanine concentration ranged from 523 to $1,540 \mu \mathrm{mol} /$ liter in PKU, 402 to 533 in HPA, and 49 to 54 in controls. Subjects with classical PKU hydroxylated mean \pm SD 4.8 \pm 2.2 $\mu \mathrm{mol} / \mathrm{kg}$ per $\mathrm{h}$ (range 0.9-8.4) of phenylalanine to tyrosine and those with HPA 4.4 and 5.3, respectively. These rates were substantial in comparison with those in controls (6.3 \pm 1.6 , 3.2-8.2). The significant hydroxylation in PKU and HPA subjects is likely to result from induction of activity of tyrosine hydroxylase towards phenylalanine by the greatly elevated phenylalanine concentration. The presence of such activity in PKU suggests that therapy aimed at promotion of this usually latent hydroxylating capacity may be a future alternative to dietary treatment of PKU. (J. Clin. Invest. 1990. 86:317-322.) Key words: enzyme $\bullet$ stable isotope $\bullet\left[{ }^{2} \mathbf{H}_{5}\right]$ phenylalanine $\bullet$ hyperphenylalaninemia $\bullet$ tyrosine hydroxylase
\end{abstract}

\section{Introduction}

Phenylketonuria (PKU) ${ }^{1}$ is one of the most common inborn errors of metabolism in man (1). Phenylalanine hydroxylase, the deficient enzyme in classical PKU, is present in significant quantities only in the liver, and is not expressed in skin fibroblasts (2). The frequency of PKU ( 1/10,000 live births [1]) has led to extensive exploration for reliable methods of detecting various hyperphenylalaninemic phenotypes. Measurement of phenylalanine hydroxylase activity in liver has allowed discrimination of some phenotypes (3-5), but the invasiveness of liver biopsy precludes the technique from routine use. Consequently, a number of in vivo methods have been investigated (6-19). These techniques have, in general, attempted to assess

Address reprint requests to Dr. Thompson, The Murdoch Institute, Royal Children's Hospital, Flemington Road, Parkville, Victoria 3052, Australia.

Received for publication 11 July 1989 and in revised form 23 January 1990.

1. Abbreviations used in this paper: HPA, hyperphenylalaninemia; PKU, phenylketonuria.

J. Clin. Invest.

(c) The American Society for Clinical Investigation, Inc.

0021-9738/90/07/0317/06 \$2.00

Volume 86, July 1990, 317-322 the ability to clear phenylalanine from plasma or to hydroxylate it to tyrosine. A number of studies have examined the response in plasma phenylalanine and/or tyrosine following an oral or intravenous load of phenylalanine $(8,11,12$, 16-18), but these tests fail to discriminate between normal and heterozygote subjects in a substantial number of cases. Better discrimination has more recently been obtained by various deuterated phenylalanine loading techniques $(7,13,19)$. Estimates of in vivo enzyme activity using these methods suggest that PKU carriers have $\sim 50 \%$ of normal in vivo phenylalanine hydroxylase activity, subjects with hyperphenylalaninemia (HPA, a mild PKU variant) have $\sim 10 \%$ of normal activity, and subjects with classical PKU have between 0.3 and $3 \%$ of normal activity. These results are similar to those found in vitro in liver, where HPA and PKU subjects have enzyme activities of about $5 \%$ and $<1 \%$ of normal, respectively (20). The implication of these findings is that patients with classical PKU cannot hydroxylate significant quantities of phenylalanine in vivo. There are, however, several concerns regarding this conclusion.

Loading tests with labeled and unlabeled substrates may be influenced by a number of physiological variables additional to phenylalanine hydroxylase activity itself, such as changes in protein metabolism, urinary excretion, transamination rates, phenylalanine distribution, and transport and hormonal influences. These factors have been discussed in detail previously (2). There are in addition several concerns related particularly to labeled phenylalanine bolus methods. Clarke and Bier (21) and Thompson et al. (22) have shown that in normal individuals phenylalanine hydroxylation calculated using techniques based on low-dose continuous infusion of $\left[{ }^{2} \mathrm{H}_{5}\right]$ phenylalanine is between three and five times lower than that calculated from data presented by various authors using bolus techniques (12, $14,17,23)$. This is consistent with the induction of phenylalanine hydroxylase in vivo by the acute increases in phenylalanine concentration that arise from the bolus dose, a response also seen in vitro (24). The in vivo enzyme activity measured by bolus techniques will thus be above the basal physiological level. A further objection to the bolus technique is that equilibration within the whole body precursor pool (21) and between precursor and product is not achieved (9). In particular, there is a delay in equilibration of deuterated tyrosine in the liver with that in plasma (14), so that events at the sampling site do not immediately reflect those at the hydroxylation site. Finally, the concept of using a fixed dose of labeled phenylalanine and measurement of the plasma concentration of labeled tyrosine alone to determine in vivo hydroxylase activity (19) is unsound because the calculated activity will also be influenced simply by the increased pool size in PKU and HPA, as demonstrated in Fig. 1. Hence, while bolus methods are advantageous particularly in discriminating between PKU heterozygotes and normal subjects, their application to the direct measurement of enzyme activity in vivo may be limited. 


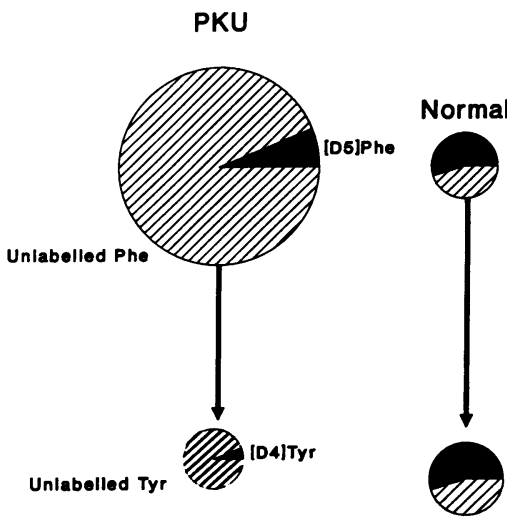

Figure 1. Measurement of in vivo hydroxylase activity using a fixed bolus dose of $\left[{ }^{2} \mathrm{H}_{5}\right]$ phenylalanine and determination of plasma concentration of $\left[{ }^{2} \mathrm{H}_{4}\right]$ tyrosine alone (19). For a given dose of $\left[{ }^{2} \mathrm{H}_{5}\right]$ phenylalanine the enrichment of the large whole body phenylalanine pool in PKU will be much lower than that in a subject with normal plasma phenylala-

nine concentration. Hence, at a given hydroxylation rate, both the concentration and enrichment of $\left[{ }^{2} \mathrm{H}_{4}\right]$ tyrosine in plasma will be substantially lower in PKU than in controls. The low "hydroxylation" rates measured using this technique in PKU thus reflect not only the decreased phenylalanine hydroxylase activity, but also the increased phenylalanine pool size.

The administration of a labeled substrate by continuous infusion at "tracer" doses would be expected to have a less profound effect on in vivo kinetics. This proposal has been confirmed by Tessari et al. (25) for leucine kinetics, a system that is particularly sensitive to changes in substrate concentration (26). Inherent in the concept of the continuous infusion technique is that the substrate pool size has no effect on kinetic calculations so long as isotopic plateau is achieved (27). Further, equilibration of the enrichments of the free precursor pool and between precursor and product can be verified by examining the isotopic enrichment plateaus of the respective compounds. We have therefore used continuous infusions of stable isotopically labeled compounds to determine in vivo phenylalanine hydroxylating activity in PKU, HPA, and control subjects under basal physiological conditions.

\section{Methods}

\section{Subjects}

The studies were approved by the Harrow District Ethical Committee. 10 adults with PKU and 2 with HPA were studied. Their details are shown in Table I. All were of normal intelligence. Clinical severity was determined from the dietary tolerance for phenylalanine, defined as the highest intake $(\mathrm{mg} / \mathrm{kg})$ consistent with acceptable plasma levels of phenylalanine (200-400 $\mu \mathrm{mol} / \mathrm{liter})$. Most PKU subjects had relaxed strict dietary control at the time of study. Phenylalanine tolerance in these subjects was determined retrospectively from an earlier period of good dietary control between the ages of 6 and $10 \mathrm{yr}$ or over $18 \mathrm{yr}$. Results were compared with those in six normal adults (mean age 36 yr, range 25-49, five males, one female) who have been described previously (22). All had fasting plasma phenylalanine/tyrosine concentration ratios of less than 1, making carrier status for PKU unlikely (13). Dietary intake of phenylalanine was assessed at the time of study by recall dietary history or, where history was uncertain, by 3-d diet diary.

\section{Measurement of hydroxylation rates}

Isotopes. L-[ring- ${ }^{2} \mathrm{H}_{5}$ ]Phenylalanine $\left(98 \%{ }^{2} \mathrm{H}\right), \mathrm{L}$-[ring- $\left.{ }^{2} \mathrm{H}_{4}\right]$ tyrosine $\left(98 \%{ }^{2} \mathrm{H}\right)$ and $\mathrm{L}-\left[3,5-{ }^{2} \mathrm{H}_{2}\right]$ tyrosine $\left(98 \%{ }^{2} \mathrm{H}\right)$ were obtained from Cambridge Isotopes Laboratories (Woburn, MA). The isotopic and isomeric purities of the isotopes were verified by gas chromatography/ mass spectrometry and by chiral column gas chromatography, respectively. Isotopes were infused in a solution of normal saline that was shown to be sterile and pyrogen free.

Procedure. All subjects were studied when well. After an overnight fast, an intravenous cannula was inserted into a hand vein for blood collection. Isotopes were infused into a vein in the opposite hand. After collection of a baseline blood sample, subjects received intravenous priming bolus doses of $\left[{ }^{2} \mathrm{H}_{5}\right]$ phenylalanine (PKU variable dose, see below, control $0.5 \mathrm{mg} / \mathrm{kg}),\left[{ }^{2} \mathrm{H}_{2}\right]$ tyrosine $(0.25 \mathrm{mg} / \mathrm{kg}$, all subjects $)$ and $\left[{ }^{2} \mathrm{H}_{4}\right]$ tyrosine $\left(0.08 \mathrm{mg} / \mathrm{kg}\right.$, controls only). The $\left[{ }^{2} \mathrm{H}_{5}\right]$ phenylalanine priming dose in PKU and HPA was calculated from the plasma phenylalanine concentration determined $1 \mathrm{wk}$ before the study using the following formula:

Priming dose $(\mathrm{mg} / \mathrm{kg})$

$$
=\underline{\text { phenylalanine concentration }(\mu \mathrm{mol} / \mathrm{liter}) \times 0.5 \times \text { weight }(\mathrm{kg})}
$$

Table I. Details of Subjects

\begin{tabular}{|c|c|c|c|c|c|c|c|c|}
\hline \multirow[b]{2}{*}{ Subject } & \multirow[b]{2}{*}{ Age } & \multirow[b]{2}{*}{ Sex } & \multirow[b]{2}{*}{ Height } & \multirow[b]{2}{*}{ Weight } & \multicolumn{2}{|c|}{ Dietary phe* } & \multicolumn{2}{|c|}{ Plasma concentration ${ }^{\ddagger}$} \\
\hline & & & & & Tolerance & Intake & Phe & Tyr \\
\hline & $y r$ & & $\mathrm{~cm}$ & $\mathrm{~kg}$ & & & & \\
\hline \multicolumn{9}{|l|}{ PKU } \\
\hline 1 & 17 & $\mathbf{M}$ & 175 & 65.9 & 5 & 48 & 1,410 & 18 \\
\hline 2 & 20 & $\mathbf{M}$ & 173 & 59.5 & 6 & 17 & 951 & 21 \\
\hline 3 & 18 & $\mathbf{M}$ & 176 & 56.7 & 6 & 6 & 523 & 20 \\
\hline 4 & 22 & $\mathbf{M}$ & 175 & 67.0 & 5 & 5 & 543 & 36 \\
\hline 5 & 22 & $\mathbf{M}$ & 175 & 67.3 & 7 & 37 & 1,100 & 21 \\
\hline 6 & 20 & $\mathbf{M}$ & 170 & 56.8 & 8 & 26 & 912 & 18 \\
\hline 7 & 18 & $\mathbf{F}$ & 163 & 64.8 & 9 & 25 & 1,474 & 30 \\
\hline 8 & 18 & $\mathbf{M}$ & 169 & 51.0 & 10 & 79 & 1,540 & 22 \\
\hline 9 & 21 & $\mathbf{F}$ & 174 & 62.4 & 7 & 37 & 1,221 & 19 \\
\hline 10 & 24 & $\mathbf{M}$ & 175 & 65.1 & 6 & 77 & 1,382 & 17 \\
\hline \multicolumn{9}{|l|}{ HPA } \\
\hline 11 & 22 & $\mathbf{F}$ & 168 & 68.3 & $\mathbf{N M}$ & 52 & 533 & 31 \\
\hline 12 & 45 & $\mathbf{M}$ & 175 & 73.0 & NM & 55 & 402 & 31 \\
\hline
\end{tabular}

* Dietary intake of phenylalanine ( $\mathrm{mg} / \mathrm{kg}$ per d) as required to maintain plasma phenylalanine concentration of $200-400 \mu \mathrm{mol} / \mathrm{liter}$ (tolerance) and as at time of study (intake); ${ }^{\ddagger}$ at the time of study (NR phenylalanine 40-66, tyrosine 38-54); NM, not measured. 
This dose resulted in isotopic enrichment plateau of $\left[{ }^{2} \mathrm{H}_{5}\right]$ phenylalanine being achieved within the study period in most cases (see Results). Priming doses were followed by continuous infusion of $\left[{ }^{2} \mathrm{H}_{5}\right]$ phenylalanine $\left(0.5 \mathrm{mg} / \mathrm{kg}\right.$ per h) and $\left[{ }^{2} \mathrm{H}_{2}\right]$ tyrosine $(0.25 \mathrm{mg} / \mathrm{kg}$ per h). The infusion was given over the standard period of $4 \mathrm{~h}$ in controls. However, the expanded phenylalanine pool in PKU and HPA delayed the achievement of isotopic equilibration of $\left[{ }^{2} \mathrm{H}_{5}\right]$ phenylalanine, so that infusions were given over $6 \mathrm{~h}$. Blood samples were collected at 15-20min intervals in the final $2 \mathrm{~h}$ of each infusion and, in PKU and HPA, at half-hourly intervals between $1 \frac{1 / 2}{2}$ and $4 \mathrm{~h}$ after starting the infusion.

Analyses. Blood samples were centrifuged at $4^{\circ} \mathrm{C}$ immediately after collection and the plasma stored at $-70^{\circ} \mathrm{C}$ until analyzed. Plasma phenylalanine and tyrosine concentrations and deuterium enrichments were measured using tertiarybutyl-dimethylsilyl derivatives and a Finnigan $\mathbf{4 5 0 0}$ gas chromatograph/mass spectrometer as previously described (22). The possibility of deuterium label exchange in labeled phenylalanine and tyrosine species in vivo was monitored by selected ion monitoring of $\left[{ }^{2} \mathrm{H}_{1}\right],\left[{ }^{2} \mathrm{H}_{2}\right],\left[{ }^{2} \mathrm{H}_{3}\right]$, and $\left[{ }^{2} \mathrm{H}_{4}\right]$ channels as appropriate. There was no evidence of label exchange in vivo in any subject.

Calculations. Phenylalanine hydroxylation $(\mu \mathrm{mol} / \mathrm{kg}$ per $\mathrm{h})$ was determined from the plateau enrichments of $\left[{ }^{2} \mathrm{H}_{5}\right]$ phenylalanine $(E p)$ and $\left[{ }^{2} \mathrm{H}_{4}\right]$ tyrosine $(E t)$ in plasma during continuous infusion of $\left[{ }^{2} \mathrm{H}_{5}\right]$ phenylalanine in a similar manner to that described previously (21):

Hydroxylation $=Q t \times \frac{E \mathrm{t}}{E \mathrm{p}}$

where $Q t$ is the tyrosine flux ( $\mu \mathrm{mol} / \mathrm{kg}$ per $\mathrm{h}$ ) determined independently from the continuous infusion of $\left[{ }^{2} \mathrm{H}_{2}\right]$ tyrosine:

$Q t=i \cdot\left[\frac{E \mathrm{i}}{E_{\mathrm{D} 2 \mathrm{tyr}}}-1\right]$

where $i$ is the rate of infusion of $\left[{ }^{2} \mathrm{H}_{2}\right]$ tyrosine $(\mu \mathrm{mol} / \mathrm{kg}$ per h) and $E \mathrm{i}$ and $E_{\mathrm{D} 2 \mathrm{tyr}}$ are the respective enrichments of $\left[{ }^{2} \mathrm{H}_{2}\right]$ tyrosine in the infusate and at plateau in plasma.

There is considerable, but as yet inconclusive, debate regarding the relationship between the enrichments of amino acids in plasma and in the precursor pool for their further metabolism. These concerns have been most widely investigated with respect to leucine oxidation (summarized in 22, 27), but probably also apply to the determination of phenylalanine hydroxylation. Absolute plasma enrichments of the various deuterated species were used for determination of hydroxylation rates rather than adopting correction factors as have been proposed elsewhere for specific substrates $(22,28)$. Hence the values presented here may not be truly representative of the absolute hydroxylation rate. However, the concerns referred to above appear to be consistent between subjects with differing conditions for leucine kinetics (29), and therefore probably also for phenylalanine kinetics, so that comparison between the conditions studied here should be valid.

\section{Results}

Plasma isotopic enrichments of $\left[{ }^{2} \mathrm{H}_{5}\right]$ phenylalanine, $\left[{ }^{2} \mathrm{H}_{4}\right]$ tyrosine and $\left[{ }^{2} \mathrm{H}_{2}\right]$ tyrosine are shown for each subject in Table II. In all subjects the enrichments were maintained within a close range over the final $2 \mathrm{~h}$ of the study, satisfying generally accepted criteria for achievement of plateau (coefficient of variation $<10 \%$, sequential changes in opposite directions, visual inspection). In subjects with high plasma phenylalanine concentrations ( $>1,000 \mu \mathrm{mol} /$ liter), however, the size of the free phenylalanine pool ( $>500 \mu \mathrm{mol} / \mathrm{kg}$ ) in relation to its rate of turnover $(\sim 40 \mu \mathrm{mol} / \mathrm{kg}$ per $\mathrm{h})$ suggested that the apparent plateau plasma enrichment may not be representative of equilibration between infused and endogenous phenylalanine appearance. In these circumstances the rate of change of the $\left[{ }^{2} \mathrm{H}_{5}\right]$ phenylalanine enrichment with time would be very slow, so that once the labeled compound had equilibrated with the free phenylalanine pool itself, an apparent isotopic plateau would be seen over a 6-h study period. Calculations of phenylalanine flux (results not shown) from the plasma phenylalanine enrichment in some subjects with high phenylalanine concentrations were substantially different from those that would be predicted from protein kinetics in normal subjects and from protein composition (22). The departure from predicted values was greatest when the plasma phenylalanine concentration at the time of study differed from that used to calculate the $\left[{ }^{2} \mathrm{H}_{5}\right]$ phenylalanine priming dose (Eq. 1).

Despite the lack of true equilibration of $\left[{ }^{2} \mathrm{H}_{5}\right]$ phenylalanine enrichment in some subjects, isotopic plateau of both labeled tyrosine species was achieved in all subjects. As the tyrosine pool size is usually decreased in PKU (30), equilibration of tyrosine enrichments should be more rapid than in normal subjects (22). The plateau enrichments measured in PKU and HPA should therefore represent true equilibration between endogenously appearing tyrosine and that appearing from the infusion or from $\left[{ }^{2} \mathrm{H}_{5}\right]$ phenylalanine hydroxylation. Calculation of phenylalanine hydroxylation using Eqs. 2 and 3 depends on attaining equilibration of $\left[{ }^{2} \mathrm{H}_{2}\right]$ tyrosine and $\left[{ }^{2} \mathrm{H}_{4}\right]$ tyrosine enrichments. However, it is necessary only that the $\left[{ }^{2} \mathrm{H}_{5}\right]$ phenylalanine enrichment does not change significantly during the period over which calculations are made, and that this labeled compound is thoroughly mixed with the precursor pool for phenylalanine hydroxylation. The latter assumption appears to be reasonable in the current studies in that $\left[{ }^{2} \mathrm{H}_{4}\right]$ tyrosine enrichment plateau would not have been achieved were mixing to have been incomplete. Hence, the conditions used here should allow valid measurement of in vivo phenylalanine hydroxylation, but not necessarily of phenylalanine flux, in PKU subjects. Tyrosine flux values in PKU subjects were generally lower than those in controls (Table II). This decrease presumably reflects the expected decrease in protein turnover in PKU which would be likely to result from lower protein intakes (31) and/or increased phenylalanine concentration (32).

Significant in vivo phenylalanine hydroxylation was achieved in all PKU and HPA subjects, with absolute rates often equating with those in controls, and the mean activity being about half that in controls (Table II). The $\left[{ }^{2} \mathrm{H}_{4}\right]$ tyrosine pool was not primed in PKU subjects, in contrast to the procedure in controls, so that all $\left[{ }^{2} \mathrm{H}_{4}\right]$ tyrosine appearing in plasma in PKU must have been derived by hydroxylation of $\left[{ }^{2} \mathrm{H}_{5}\right]$ phenylalanine. There did not appear to be a significant relationship between the hydroxylation rate and phenylalanine concentration (Fig. 2). Hydroxylation rates in the two subjects with HPA were within the control range.

\section{Discussion}

This study has measured the rate of appearance of $\left[{ }^{2} \mathrm{H}_{4}\right]$ tyrosine during continuous infusion of $\left[{ }^{2} \mathrm{H}_{5}\right]$ phenylalanine to show that phenylalanine can be hydroxylated to tyrosine in significant quantities in vivo in patients with classical features of PKU. The appearance of deuterated tyrosine in plasma has been noted previously in PKU after bolus administration of deuterated phenylalanine $(7,19)$, but these studies suggested that the hydroxylation was quantitatively insignificant. The 
Table II. Isotopic Enrichment, Tyrosine Flux, and Phenylalanine Hydroxylation Measurements

\begin{tabular}{|c|c|c|c|c|c|}
\hline \multirow[b]{2}{*}{ Subjects } & \multicolumn{3}{|c|}{ Plasma enrichment (MPE) } & \multirow{2}{*}{$\begin{array}{l}\text { Tyrosine } \\
\text { flux }\end{array}$} & \multirow{2}{*}{$\begin{array}{l}\text { Phenylalanine } \\
\text { hydroxylation }\end{array}$} \\
\hline & {$\left[{ }^{2} \mathrm{H}_{5}\right] \mathrm{Phe}$} & {$\left[{ }^{2} \mathrm{H}_{4}\right] \mathrm{Tyr}$} & {$\left[{ }^{2} \mathrm{H}_{2}\right] \mathrm{Tyr}$} & & \\
\hline & & & & & \\
\hline \multicolumn{6}{|l|}{ PKU } \\
\hline 1 & 5.6 & 1.5 & 6.0 & 17.4 & 4.6 \\
\hline 2 & 5.5 & 0.1 & 4.2 & 35.0 & 0.9 \\
\hline 3 & 4.1 & 1.1 & 4.1 & 23.7 & 6.5 \\
\hline 4 & 6.7 & 1.2 & 4.8 & 21.0 & 3.7 \\
\hline 5 & 3.7 & 1.3 & 5.2 & 22.0 & 7.8 \\
\hline 6 & 5.0 & 1.3 & 5.6 & 19.8 & 5.3 \\
\hline 7 & 8.9 & 1.5 & 5.9 & 17.6 & 2.9 \\
\hline 8 & 4.4 & 0.9 & 3.1 & 39.1 & 8.4 \\
\hline 9 & 6.1 & 1.2 & 4.4 & 16.8 & 3.2 \\
\hline 10 & 6.6 & 1.0 & 3.4 & 31.9 & 4.8 \\
\hline Mean & 5.7 & 1.1 & 4.7 & 24.4 & 4.8 \\
\hline SD & 1.5 & 0.4 & 1.0 & 7.6 & 2.2 \\
\hline \multicolumn{6}{|l|}{ HPA } \\
\hline 11 & 8.3 & 1.5 & 4.4 & 24.7 & 4.4 \\
\hline 12 & 6.3 & 1.4 & 4.5 & 24.5 & 5.3 \\
\hline \multicolumn{6}{|c|}{ Controls $(n=6)$} \\
\hline Mean & 7.9 & 1.7 & 4.2 & 30.9 & 6.3 \\
\hline SD & 1.1 & 0.2 & 0.4 & 3.6 & 1.6 \\
\hline Range & $6.6-10.3$ & $1.1-1.8$ & $3.7-5.4$ & $26.8-36.1$ & $3.2-8.2$ \\
\hline
\end{tabular}

current study has used techniques to overcome the apparent limitations of bolus methods in quantitating in vivo enzyme activity and has demonstrated that, in many cases, absolute phenylalanine hydroxylation rates in PKU are similar to those in controls. In contrast to controls, however, these in vivo enzyme activities were achieved at elevated substrate concentrations that would be expected to induce maximal or near maximal enzyme stimulation. Control values were therefore not directly comparable in that they were measured basally at normal substrate concentrations. It is likely that controls would have achieved vastly greater hydroxylation rates if subjected to the whole body load of phenylalanine that is present in PKU subjects, given that basal hydroxylation rates are normally well below the theoretical maximum (see below, Table III). Comparison between the rates in PKU and controls, however, establishes the physiological significance of the in vivo activity in PKU.

Phenylalanine hydroxylation in PKU appears to proceed at an approximately equivalent rate to the urinary excretion

Table III. In Vivo Phenylalanine Hydroxylation in PKU and Normal Subjects Measured and Predicted by Various Techniques

\begin{tabular}{|c|c|c|}
\hline Technique & Control & PKU \\
\hline $\begin{array}{l}\text { In vitro hepatic phenylalanin } \\
\text { (theoretical maximum)* }\end{array}$ & 110 & $<0.6$ \\
\hline In vivo bolus ${ }^{\ddagger}$ & $14-25$ & $<1$ \\
\hline In vivo continuous infusion $\$$ & $3-8$ & $1-8$ \\
\hline
\end{tabular}

All units are $\mu \mathrm{mol} / \mathrm{kg}$ per $\mathrm{h} .{ }^{*}$ Calculated as described in text. ${ }^{\ddagger}$ Refs. $(12,14,17,23),{ }^{8}$ refs. $(21,22$, current study). rates of the various characteristic PKU urinary metabolites such as phenyllactate, phenylacetate and phenylpyruvate. Excretion rates of these compounds in PKU subjects receiving unrestricted phenylalanine intakes can be calculated to approximate $4 \mu \mathrm{mol} / \mathrm{kg}$ per h (33), while the urinary excretion of phenylalanine is $\sim 1 \mu \mathrm{mol} / \mathrm{kg}$ per $\mathrm{h}$ in untreated PKU (34). On the other hand, the mean phenylalanine intake of a subject consuming $1 \mathrm{~g} / \mathrm{kg}$ per $\mathrm{d}$ of protein composed of $4 \%$ phenylalanine can be calculated to be $9.2 \mu \mathrm{mol} / \mathrm{kg}$ per $\mathrm{h}$. In adult subjects in net nitrogen balance, this intake must be disposed of by routes additional to urinary excretion if whole body phenylalanine balance is to be maintained. The hydroxylation rates measured in the current study suggest that in PKU a substantial proportion of phenylalanine is disposed of through metabolism to tyrosine rather than to urinary metabolites.

Phenylalanine is probably converted to tyrosine in PKU through hydroxylating mechanisms other than the phenylalanine hydroxylase enzyme. It may be calculated that the maximum available activity of phenylalanine hydroxylase in the liver of a normal $70-\mathrm{kg}$ adult would be $\sim 110 \mu \mathrm{mol}$ tyrosine produced $/ \mathrm{kg}$ body weight per $\mathrm{h}$, assuming a liver weight of 1.5 $\mathrm{kg}$ of which $6 \%$ is protein and a maximal in vitro hydroxylase activity of $90 \mu \mathrm{mol} / \mathrm{h}$ per $\mathrm{g}$ liver protein (4). In classical PKU the hepatic enzyme activity is reduced to $<0.5 \%$ of normal values (35), so that even under ideal conditions the residual enzyme is capable of hydroxylating $<0.6 \mu \mathrm{mol} / \mathrm{kg}$ per $\mathrm{h}$ of phenylalanine. Tyrosine hydroxylase is known to have the capacity to hydroxylate phenylalanine (36), and at high substrate concentrations this alternate pathway is a plausible mechanism by which phenylalanine could be hydroxylated in PKU. It remains possible, however, that hydroxylation could proceed through other hydroxylases such as tryptophan hydroxylase. 
Phenylalanine hydroxylation in some PKU subjects was similar to that measured in controls. Although we are not aware that phenylalanine hydroxylation has been measured in the fed state, it is likely that in normal subjects rates would increase substantially as they do for leucine oxidation, which more than doubles in the fed state (37). The basally high phenylalanine concentrations in PKU would suggest that concentration-dependent hydroxylation is already maximal in the fasted state, so that feeding should result in little further increase. Hence postprandial increases in hydroxylation in normal subjects would result in overall daily phenylalanine hydroxylation rates substantially higher than those seen even in the PKU subjects with high enzyme activities.

The hydroxylation rates in PKU appeared to bear little relationship to the phenylalanine concentration (Fig. 2), and hydroxylation activity in HPA was similar to that in PKU. These findings suggest that the mechanisms by which residual enzyme and alternate pathway hydroxylating activities are activated are complex and depend on factors in addition to the phenylalanine concentration. For example, it is likely that there may be some variation in residual enzyme activity even in subjects with classical PKU (4). Alternatively, it is possible that hydroxylation through alternate pathway enzymes such as tyrosine hydroxylase could vary between individuals at a given phenylalanine concentration, possibly through genetic polymorphism. Such polymorphism could explain why different individuals with classical PKU achieve different peak phenylalanine concentrations when receiving similar unrestricted phenylalanine intakes. However, it is likely that the plasma phenylalanine concentration within an individual reflects a state of equilibrium between rates of hydroxylation and of input and removal of phenylalanine by other routes, so that hydroxylation would increase with increasing phenylalanine concentration. The cross-sectional design of the current study would not be expected to reveal such concentration dependency.

A number of alternative approaches to treatment of PKU have been proposed previously, including the administration of branched-chain amino acids to reduce the entry of phenylalanine into the central nervous system (38), the administration of beta-2-thienylamine to promote renal excretion and inhibit intestinal absorption of phenylalanine (39) and the use of vascular shunts containing phenylalanine ammonia lyase (40), although none of these have become acceptable for clinical use. The presence of significant hydroxylation in PKU subjects

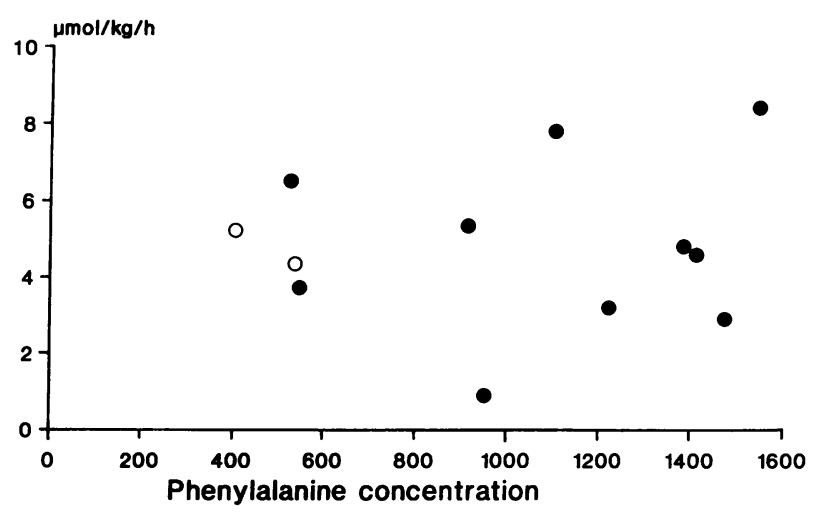

Figure 2. Relationship between phenylalanine concentration ( $\mu \mathrm{mol} /$ liter) and hydroxylation in PKU (๑) and HPA (O) subjects. in this study indicates a possible benefit of therapies aimed at inducing alternate pathway activity. Such therapy could be directed towards induction of tyrosine hydroxylase or other hydroxylases.

In summary, the current study suggests that the phenylalanine hydroxylating system in man involves more components than the phenylalanine hydroxylase enzyme alone. The apparent existence of additional hydroxylation pathways opens the possibility of developing alternative therapies in disorders of phenylalanine metabolism.

\section{Acknowledgments}

We are grateful to Miss H. Merritt and Mr. G. C. Ford for their technical assistance, to Miss P. Bingham for her dietetic assistance and to Dr. D. P. Brenton and Dr. I. Smith for their comments and for allowing access to their patients.

\section{References}

1. Tourian, A., and J. B. Sidbury. 1983. Phenylketonuria and hyperphenylalaninaemia. In The Metabolic Basis of Inherited Disease. J. B. Stanbury, J. B. Wyngaarden, D. S. Frederickson, J. L. Goldstein, and M. S. Brown, editors. 5th ed. McGraw-Hill Book Co., New York. 270-286.

2. Güttler, F. 1980. Hyperphenylalaninaemia: diagnosis and classification of the various phenotypes of phenylalanine hydroxylase deficiency in childhood. Acta Paediatr. Scand. 280(Suppl.):1-80.

3. Kaufman, S., and E. E. Max. 1975. Phenylalanine hydroxylase activity in liver biopsies from hyperphenylalaninaemia heterozygotes: deviation from proportionality with gene dosage. Pediatr. Res. 9:632634.

4. Bartholomé, K., P. Lutz, and H. Bickel. 1975. Determination of phenylalanine hydroxylase activity in patients with phenylketonuria and hyperphenylalaninemia. Pediatr. Res. 9:899-903.

5. Largilliere, C., J. L. Dhondt, and J. P. Farriaux. 1986. Hepatic phenylalanine hydroxylase and dietary tolerance in hyperphenylalaninaemic patients. J. Inher. Metab. Dis. 9:207-211.

6. Curtius, H. 1982. In vivo measurement of enzymes with deuterated precursors and GC/SIM. In Stable Isotopes. H. L. Schmidt, H. Förstel, and K. Heinzinger, editors. Elsevier Scientific Publishing Co., Amsterdam. 277-286.

7. Curtius, H., M. J. Zagalak, K. Baerlocher, J. Schaub, W. Leimbacher, and U. Redweik. 1977. In vivo studies of the phenylalanine-4hydroxylase system in hyperphenylalaninemics and phenylketonurics. Helv. Pediatr. Acta. 32:461-469.

8. Blitzer, M. G., J. E. Bailey-Wilson, and E. Shapira. 1985. Discrimination of phenylketonurics from persistent hyperphenylalaninemia using a simple loading test. Clin. Chim. Acta. 153:137-142.

9. Lehman, W. D., and H. C. Heinrich. 1985. Oral versus intravenous L-phenylalanine loading compared by simultaneous application of $\mathrm{L}-\left[{ }^{2} \mathrm{H}_{5}\right]$ phenylalanine and $\mathrm{L}-\left[{ }^{15} \mathrm{~N}\right]$ phenylalanine. Clin. Chim. Acta. 147:261-266.

10. Griffin, R. F., and L. J. Elsas. 1975. Classic phenylketonuria: diagnosis through heterozygote detection. J. Pediatr. 86:512-517.

11. Rampini, S., P. W. Anders, H.-Ch. Curtius, and Th. Marthaler. 1969. Detection of heterozygotes for phenylketonuria by column chromatography and discriminatory analysis. Pediatr. Res. 3:287-297.

12. Bremer, H. J., and W. Neumann. 1966. Tolerance of phenylalanine after intravenous administration in phenylketonurics, heterozygous carriers and normal adults. Nature (Lond.). 209:1148-1149.

13. Lehmann, W. D., N. Theobald, H. C. Heinrich, P. Clemens, and R. Grüttner. 1984. Detection of heterozygous carriers for phenylketonuria by a $\mathrm{L}-\left[{ }^{2} \mathrm{H}_{5}\right]$ phenylalanine stable isotope loading test. Clin. Chim. Acta. 138:59-71.

14. Fell, V., J. A. Hoskins, and R. J. Pollitt. 1978. The labelling of 
urinary acids after oral doses of deuterated L-phenylalanine and L-tyrosine in normal subjects. Quantitative studies with implications for the deuterated phenylalanine loading test in phenylketonuria. Clin. Chim. Acta. 83:259-269.

15. Hsieh, M. C., H. K. Berry, M. K. Bofinger, P. J. Phillips, M. B. Guilfoile, and M. M. Hunt. 1983. Comparitive diagnostic value of phenylalanine challenge and phenylalanine hydroxylase activity in phenylketonuria. Clin. Genet. 23:415-421.

16. Westwood, A., and D. Raine. 1975. Heterozygote detection in phenylketonuria. J. Med. Genet. 12:327-333.

17. Jagenburg, R., C. G. Regardh, and S. Rödjer. 1977. Detection of heterozygotes for phenylketonuria. Total body phenylalanine clearance and concentrations of phenylalanine and tyrosine in the plasma of fasting subjects compared. Clin. Chem. 23:1654-1660.

18. Matalon, R., D. E. Matthews, K. Michals, and D. Bier. 1982. The use of deuterated phenylalanine for the in vivo assay of phenylalanine hydroxylase activity in children. J. Inher. Metab. Dis. 5:17-19.

19. Trefz, F. K., T. Erlenmaier, D. H. Hunneman, K. Bartholomé, and P. Lutz. 1979. Sensitive in vivo assay of the phenylalanine hydroxylating system with a small intravenous dose of heptadeutero Lphenylalanine using high pressure liquid chromatography and capillary gas chromatography/mass fragmentography. Clin. Chim. Acta. 99:211-220.

20. Rey, F., A. Munnich, S. Lyonnet, and J. Rey. 1987. Classification et hétérogénéité des hyperphénylalaninémies liées à un déficit en phénylalanine hydroxylase. Arch. Fr. Pediatr. 44:639-642.

21. Clarke, J. T. R., and D. M. Bier. 1982. The conversion of phenylalanine to tyrosine in man. Direct measurement by continuous intravenous tracer infusions of L-[ring- ${ }^{2} \mathrm{H}_{5}$ ]phenylalanine and L- $\left[1-{ }^{13} \mathrm{C}\right]$ tyrosine in the postabsorptive state. Metab. Clin. Exp. 31:999-1005.

22. Thompson, G. N., P. J. Pacy, H. Merritt, G. C. Ford, M. A. Read, K. N. Cheng, and D. Halliday. 1989. Rapid measurement of whole body and forearm protein turnover using a phenylalanine model. Am. J. Physiol. 256:E631-639.

23. Trefz, F. K., D. J. Byrd, M. E. Blaskovics, W. Kochen, and P. Lutz. 1976. Determination of deuterium labeled phenylalanine and tyrosine in human plasma with high pressure liquid chromatography and mass spectrometry. Clin. Chim. Acta. 73:431-438.

24. Shiman, R., and D. W. Gray. 1980. Substrate activation of phenylalanine hydroxylase. A kinetic characterisation. J. Biol. Chem. 255:4793-4800.

25. Tessari, P., E. Tsalikian, W. F. Schwenk, S. L. Nissen, and M. W. Haymond. 1985. Effects of $\left[{ }^{15} \mathrm{~N}\right]$ leucine infused at low rates on leucine metabolism in humans. Am. J. Physiol. 249:E121-130.

26. Meguid, M. M., D. E. Matthews, D. M. Bier, C. N. Meredith, J. S. Soeldner, and V. R. Young. 1986. Leucine kinetics at graded leucine intakes in young men. Am. J. Clin. Nutr. 43:770-780.

27. Wolfe, R. R., 1984. Tracers in Metabolic Research. Alan R. Liss. New York. pp. 287.
28. Matthews, D. E., H. P. Schwarz, R. D. Yang, K. J. Motil, V. R. Young, and D. M. Bier. 1982. Relationship of plasma leucine and $\alpha$-ketoisocaproic acid during a $\mathrm{L}-\left[1-{ }^{13} \mathrm{C}\right]$ leucine infusion in man: a method for measuring human intracellular leucine tracer enrichment. Metab. Clin. Exp. 31:1105-1112.

29. Thompson, G. N., P. J. Pacy, G. C. Ford, H. Merritt, and D. Halliday. 1989. Relationships between plasma isotopic enrichments of leucine and alpha-ketoisocaproic acid during continuous infusion of labelled leucine. Eur. J. Clin. Invest. 18:639-643.

30. Kindt, E., H. A. Lunde, L. R. Gjessing, S. Halvorsen, and S. O. Lie. 1988. Fasting plasma amino acid concentrations in PKU children on two different levels of protein intake. Acta Paediatr. Scand. 77:6066.

31. Motil, K. J., D. E. Matthews, D. M. Bier, J. F. Burke, H. N. Munro, and V. R. Young. 1981. Whole body leucine and lysine metabolism: response to dietary protein intake in young men. Am. J. Physiol. 240:E712-721.

32. Okano, Y., Z. Chow, G. Isshiki, A. Inoue, and T. Oura. 1986. Effects of phenylalanine loading on protein synthesis in the fetal heart and brain of rat: an experimental approach to maternal phenylketonuria. J. Inher. Metab. Dis. 9:15-24.

33. Chalmers, R. A., and R. W. E. Watts. 1974. Quantitative studies on the urinary excretion of unconjugated aromatic acids in phenylketonuria. Clin. Chim. Acta. 55:281-294.

34. Lines, D. R., and H. A. Waisman. 1971. Urinary amino acid excretion in phenylketonuric, hyperphenylalaninemic, and normal patients. J. Pediatr. 78:474-480.

35. Friedman, P. A., D. B. Fisher, E. S. Kang, and S. Kaufman. 1973. Detection of hepatic phenylalanine 4-hydroxylase in classical phenylketonuria. Proc. Natl. Acad. Sci. USA. 70:552-556.

36. Shiman, R., M. Akino, and S. Kaufman. 1971. Solubilization and partial purification of tyrosine hydroxylase from bovine adrenal medulla. J. Biol. Chem. 246:1330-1340.

37. Rennie, M. J., R. H. T. Edwards, D. Halliday, D. E. Matthews, S. L. Wolman, and D. J. Millward. 1982. Muscle protein synthesis measured by stable isotope techniques: the effects of feeding and fasting. Clin. Sci. 63:519-523.

38. Berry, H. K., M. K. Bofinger, M. M. Hunt, P. J. Phillips, and M. B. Guilfoile. 1982. Reduction of cerebrospinal fluid phenylalanine after oral administration of valine, isoleucine and leucine. Pediatr. Res. 16:751-755.

39. Krips, C., and D. R. Lines. 1972. Phenylketonuria: reduction of serum levels of phenylalanine following oral administration of beta-2thienylamine. Aust. Paediatr. J. 8:318-321.

40. Ambrus, C. M., S. D. Sharma, C. Horvath, K. Kalgharti, S Anthone J. L. Ambrus, C. Cooley, and E. A. Mirand. 1983. In vivo safety of hollow fibre enzyme reactors with immobilized phenylalanine-ammonia-lyase in a large animal model for phenylketonuria. $J$. Pharmacol. Exp. Ther. 224:598-602. 